\title{
Educação ambiental na formação psicossocial dos jovens
}

\author{
Environmental education in psychosocial training \\ of young people
}

\author{
Winnie Gomes da Silva ${ }^{1}$ • Maria Inês Gasparetto Higuchi ${ }^{2}$ • \\ Maria Solange Moreira de Farias ${ }^{2}$
}

\begin{abstract}
Resumo: Durante 15 anos, o Laboratório de Psicologia e Educação Ambiental (Lapsea) do INPA desenvolveu o programa de educação ambiental chamado Pequenos Guias do Bosque da Ciência. O objetivo se fundamentou numa perspectiva de emancipação social e transformadora, com vistas a identificar, problematizar e agir diante de questões socioambientais. O parque zoo botânico mantido pelo INPA serviu como espaço de todas as discussões sociais e ambientais. Durante seis meses, os jovens tiveram encontros com pesquisadores e educadores e, por um ano, passaram a atuar como guias dos visitantes do parque. Este estudo foi uma avaliação desse programa, a partir de entrevistas semiestruturadas com 48 jovens das diversas turmas, desde 1994. Os resultados mostram impressionantes aspectos de transformação psicossocial e de cidadania que ocorreu com esses participantes. Foi no exercício de compartilhamento de saberes que se fundamentaram princípios para a equidade social, solidariedade, respeito e compromisso para a sustentabilidade ambiental.
\end{abstract}

Palavras-chave: Pequenos Guias do Bosque da Ciência. Educação ambiental. Desenvolvimento socioambiental.

Abstract: For 15 years, the Psychology and Environmental Education Laboratory (Lapsea - INPA), developed an environmental education program called 'Small Science Forest Guides'. The goal was based on a social and transforming empowerment perspective, in order to identify, discuss and act on social and environmental issues. The zoo botanical park maintained by the INPA served as a space for all social and environmental discussions. For six months, the young people had meetings with researchers and educators, and for a year, started to act as guides for park visitors. This study was an evaluation of the program, from semi-structured interviews with 48 young people from various groups, since 1994. The results show striking aspects of psychosocial transformation and citizenship what happened to these participants. This knowledge-sharing exercise showed to help to share principles for social justice, solidarity, respect and commitment to environmental sustainability.

Keywords: Small Science Forest Guide. Environmental education. Socio-environmental development.

\footnotetext{
${ }^{1}$ Universidade Federal de Pernambuco (UFPE), Av. Prof. Moraes Rego, 1235, Cidade Universitária, CEP 50670-901, Recife, PE, Brasil. E-mail: winniegomes@hotmail.com

${ }^{2}$ Laboratório de Psicologia e Educação Ambiental (LAPSEA), Instituto Nacional de Pesquisas da Amazônia (INPA), Manaus, AM, Brasil.
} 


\section{Introdução}

Apesar de as pessoas apresentarem uma aparente atitude positiva em relação ao meio ambiente, essas atitudes, muitas vezes, não são revertidas numa coerente práxis cotidiana (HIGUCHI, 1994). Isto acontece, justamente, porque as práticas sociais são polissêmicas, isto é, vários aspectos estão associados num determinado comportamento implícito ou explícito. $\mathrm{O}$ processo de educação ambiental é, portanto, um momento importante para o aprendizado e reavaliação de uma rede de significados, valores e conceitos sociais que permeiam nossas experiências ecológicas (REIGOTA, 1994). Um programa de Educação Ambiental (EA) em contextos não escolares, tanto quanto a escola, é um importante espaço para o processo das transformações psicossociais, que vão, inevitavelmente, desencadear comportamentos ambientais mais sustentáveis.

A EA busca desenvolver valores e habilidades para que os indivíduos adotem comportamentos ambientalmente adequados para um desenvolvimento sustentável e para melhoria da qualidade de vida de todos os povos (BARRA, 2006; JACOBI, 2003; PELICIONI, 1998). A formação do indivíduo e grupos sociais para o exercício da cidadania em sua plenitude, como uma forma de repensar a prática social de forma crítica e reflexiva, de modo que sejam capazes de identificar, problematizar, compreender, intervir sobre os problemas e conflitos ambientais, está no centro dessa proposição (CARVALHO, 2004; JACOBI, 2003; JANKE; TOZONI-REIS, 2008; REIGOTA, 2007). Embora os programas de EA possam ter diversas abordagens, seja a conservacionista ou crítica-social, é a corrente crítica, também chamada emancipatória, que está orientada para um processo permanente e coletivo de reflexão e ação, em que a ética e a sustentabilidade estão presentes para transformar a relação pessoa-ambiente (LOUREIRO, 2004).

Um programa de EA eficaz e eficiente deve ter como missão amadurecer o potencial do indivíduo como cidadão (HIGUCHI; ALVES; SACRAMENTO, 2009), uma vez que é no processo de aprendizagem que questões de cidadania e responsabilidade social são fortalecidas. Estas competências são vitais na constituição das pessoas para assimilação de mudanças, sendo autônomas em suas escolhas, respeitando as diferenças, praticando a solidariedade e superando a segregação social e desrespeito aos recursos ambientais (sejam eles referentes à natureza ou aos construídos).

$\mathrm{Na}$ prática pedagógica, esses princípios teórico-filosóficos se configuram de formas distintas, muitas vezes dissonantes até de sua proposição, seja na aplicação da formação cidadã (SAUVÉ, 2005a; SORRENTINO, 2005) ou na gestão ambiental (LAYRARGUES, 2000). As variações tratam da educação sobre o meio ambiente; no meio ambiente; para o meio ambiente e a partir do meio ambiente. Currie (1998), por sua vez, propõe a prática em EA a partir de eixos norteadores, que funcionam como um ponto de referência para o desenvolvimento dos trabalhos. A autora destaca que o primeiro eixo norteador é o papel do $e u$ no ambiente, trabalhando as responsabilidades pessoais, desenvolvendo, posteriormente, a responsabilidade nos demais contextos da vida do sujeito, como família, comunidade, município, até atingir o meio ambiente do planeta Terra. Percebe-se, portanto, um aporte pedagógico que insere o sujeito como presente e protagonista das relações pessoa-ambiente, como uma unidade indissociável.

Partindo desta problematização, este trabalho se dedicou à avaliação de um programa de EA, cujos princípios se posicionavam como transformadores, e que marcou como modelo regional de uma bem-sucedida proposta educativa. O projeto Pequenos Guias do Bosque da 
Ciência mobilizou e integrou atividades socioambientais com jovens de 10 anos a 14 anos de idade durante 15 anos. Estes eram todos provenientes das comunidades vizinhas do Bosque da Ciência, Parque Zoo-Botânico, mantido pelo Instituto Nacional de Pesquisas da Amazônia (INPA), na cidade de Manaus, Amazonas, Brasil.

Esse projeto tornou-se referência em Manaus e, literalmente, encantava todos os visitantes da cidade; as famílias traziam relatos de transformações de seus filhos e filhas a partir de sua inclusão no programa. Mesmo com tais relatos e reconhecimento público, considerou-se necessária uma avaliação sistemática dessa participação. Após 15 anos de programa, viu-se a necessidade de um estudo acompanhado de uma avaliação do processo de engajamento desses jovens, suas famílias e a própria comunidade, a fim de vislumbrar se os objetivos desenhados pelo projeto têm atingido os anseios propostos. Nesse sentido, este artigo traz uma parte da pesquisa que foi desenvolvida com apoio da Fundação de Amparo para a Pesquisa no Amazonas (FAPEAM).

\section{Os Pequenos Guias do Bosque da Ciência}

O projeto Pequenos Guias do Bosque da Ciência, iniciado em 1994 e executado por uma equipe de pesquisadores e educadores (HIGUCHI, 1994, 2003; HIGUCHI; FARIAS, 2002), se caracteriza por uma experiência de EA com mais de oitocentos meninos e meninas, distribuídos em 15 turmas, oriundos das comunidades vizinhas do Bosque da Ciência.

A motivação para o desenvolvimento do projeto se deu a partir das ocupações espontâneas da vizinhança que ameaçavam a área verde do INPA, mantida como laboratório natural de pesquisas. $\mathrm{O}$ embate se estabeleceu entre as necessidades básicas daquelas famílias que não tinham onde morar e as atividades do INPA para fins acadêmicos, e defendiam uma causa ecológica. Por conta deste conflito, a instituição identificou a necessidade de se buscarem soluções para ambos, a comunidade e o instituto.

Após uma aproximação e negociação com a comunidade, a equipe do INPA iniciou uma investigação socioeconômica, ambiental, histórica da comunidade. Além do levantamento das expectativas, necessidades e possibilidades, a fim de estabelecer uma cooperação entre os moradores. A partir deste levantamento, se identificou a preocupação dos pais em relação à educação dos filhos que entravam na adolescência e eram alvos fáceis da violência urbana (HIGUCHI; FARIAS, 2002).

Frente a esta demanda dos moradores, a equipe verificou a necessidade de integrar os jovens utilizando o espaço físico do Bosque da Ciência, previsto para ser inaugurado em 1994. Um ano antes da inauguração, os jovens começaram a participar das atividades do projeto Pequenos Guias do Bosque da Ciência.

O projeto consistiu em uma vertente socioambiental construtivista, ou seja, destaca o indivíduo e ambiente como um processo dinâmico, em que a pessoa é capaz de construir conhecimento e, ao mesmo tempo, transformar o seu meio (HIGUCHI; FARIAS, 2002). As atividades foram configuradas em três fases distintas, mas complementares:

- Formação Educacional Crítica, com duração de seis a oito meses. Nessa fase, os jovens participaram de encontros semanais com pesquisadores e educadores para discutirem questões socioculturais, ambientais e de ecoturismo. As discussões se pautavam em conflitos cognitivos- 
sociais-morais, isto é, eram apresentados diferentes cenários socioambientais, estimulando os participantes a uma reflexão e questionamento crítico. Higuchi e Farias (2002) destacam que a busca de estímulos para desenvolver o pensamento crítico embasa a construção de atitudes e valores de cidadania, e promove a atuação dos jovens na sociedade. As atividades utilizaram dinâmicas psicoeducativas, a fim de estimular a afetividade, solidariedade e cooperação pessoal, sempre observando normas e regras para comportamento assertivo, negociadas entre os participantes.

- Atuação e Interação no Bosque da Ciência, com duração de dez a 12 meses. Nessa fase, os jovens acompanhavam os visitantes pelas trilhas do Bosque, transmitindo informações simples sobre os centros de visitação e os elementos da fauna e flora local. Neste processo, o jovem se apropriava deste espaço social, internalizava e o considerava como seu, exercendo o cuidado deste ambiente e, assim, sua cidadania. É neste momento que a comunicação estabelecida, entre visitante e o pequeno guia, proporciona o reconhecimento deste jovem, pois recebe atenção, é escutado. É por meio da fala que renova e alavanca a inclusão do jovem na sociedade, que, por muitas vezes, foi negada ou imposta uma condição de inferioridade (HIGUCHI, 2003, 2008; HIGUCHI; FARIAS, 2002).

- A Participação Cidadã na Comunidade, com duração contínua, se caracterizava pela participação e mobilização dos jovens em eventos socioambientais que ocorreram na cidade. Os jovens participaram de oficinas que incluíam atitudes de solidariedade, cooperação e mobilização social. De modo especial, os participantes acabaram formando um grupo permanente, chamado Jovens Ambientalistas, que se destacam em atividades mensais no Bosque da Ciência.

Os jovens comumente são caracterizados como um grupo gerador de conflitos e de problemas. Essa representação precisa ser ressignificada, uma vez que os jovens são capazes de se posicionar na sociedade como cidadãos dinâmicos e proativos, que reivindicam, a seu modo, direitos, e podem assumir uma ética de cuidado que se manifesta por meio da cooperação e solidariedade com o outro. A partir deste pressuposto, consideramos que um projeto de EA que envolve jovens deve se fundamentar na concepção de que este público é, definitivamente, um elemento de multiplicação de mudanças em diferentes cenários, seja social e/ou ambiental. Em outras palavras, a EA “deve ser entendida como uma educação política, no sentido de que ela reivindica e prepara os cidadão/ãs para exigir justiça social, cidadania nacional e planetária, autogestão e ética nas relações sociais e com a natureza" (REIGOTA, 1994, p. 10).

Além desse pressuposto filosófico sobre o papel e função social do jovem, considera-se que a EA não se prende ao ensino em si dos ecossistemas ou aspectos científicos da formação do mundo natural ou construído. A realidade concreta em que estamos inseridos serve como ponto inicial para se transformar em mediadora e, assim, vislumbrarmos nossa condição de coabitação no planeta e na relação de compromisso e ética com todos os elementos constituintes desse sistema.

\section{Os jovens e a educação ambiental}

É comum observar, nos principais livros de psicologia do desenvolvimento, o termo adolescência ao invés de juventude (BEE, 1997; PAPALIA; OLDS; FELDMAN, 2009). Há diversas concepções de adolescência, mas, de modo geral, é definida como uma transição da 
infância para a vida adulta, marcada pelo contexto cultural e social em que irá desenrolar características psicológicas e sociais (LEVISKY, 1998; MOREIRA; ROSÁRIO; SANTOS, 2011).

Diferente da perspectiva desenvolvimentista de adolescência, o termo juventude envolve aspectos de ordem social, cultural, política, econômica e outros (MOREIRA; ROSÁRIO; SANTOS, 2011). Nesse sentido, juventude é uma categoria social, a qual pode ser compreendida como uma trajetória de vida que reflete estruturas e processos sociais; em outras palavras, abordar a temática juventude se articula com questões sociais e históricas (SILVA; LOPES, 2009).

Castro (2007) nos faz refletir sobre o papel da sociedade frente à juventude. A autora argumenta ser necessário dar visibilidade para este público no cenário social, pois irá permitir que se desenvolvam como sujeitos históricos, capazes de darem voz as suas próprias histórias.

Nesse sentido, Albuquerque (2013) e Fernandes e Higuchi (2014) chamam a atenção sobre o protagonismo juvenil, isto é, a participação cidadã desse público em diferentes atividades sociais. Os autores apontam que, dentre as atividades sociais em que os jovens estão inseridos, identificam-se as de cunho socioambiental.

Fernandes e Higuchi (2014) afirmam que a Educação Ambiental (EA) é uma forma de os jovens se constituírem protagonistas socioambientais. Albuquerque (2013) afirma que a importância atribuída aos jovens é pelo fato de reconhecê-los como capazes de perceberem criticamente o ambiente e, assim, assumirem uma postura ativa para melhoria das questões sociais.

Nesse sentido, a EA propõe transformar as interações das pessoas com o mundo humano e geofísico, o qual se constitui como um processo estratégico na formação de uma consciência crítica e de emancipação das pessoas (HIGUCHI; MOREIRA JUNIOR, 2009).

Atividades educativas nesse contexto se situam no exercício responsável da cidadania, pois está relacionado com a identidade e pertencimento de uma coletividade. A formação cidadã pode contribuir para uma sociedade democrática, justa e ecologicamente sustentável, além de respeitar a diversidade biológica e sociocultural da vida. A proposta da educação ambiental não se limita apenas ao conhecimento sobre condições ambientais favoráveis. A dimensão subjetiva está presente nesse processo educativo, possibilitando o desenvolvimento da sensibilidade em reconhecer as necessidades individuais e coletivas (JANKE; TOZONI-REIS, 2008; REIGOTA, 2007).

A partir desta ideia de propor mudanças de ordem subjetiva, Sauvé (2005b) afirma que a EA é mais do que uma educação a respeito do, para o, no, pelo ou em prol do meio ambiente; trata-se de interações que dão base para o desenvolvimento pessoal e social: interações consigo mesmo, o lugar de construção de identidade; interações com os outros, lugar da construção das relações sociais; interações com o meio de vida partilhado, lugar da educação ecológica e econômica, favorecendo a significação do "ser-no-mundo" a partir das relações com o mundo-não-humano.

Em outras palavras, é preciso considerar os aspectos psicossociais dos jovens no processo de formação. O psicossocial refere-se às vivências em uma determinada época ou momento, que podem ser: cognitivas, sociais, afetivas, capacidades e habilidades pessoais, valores e significados difundidos culturalmente (HIGUCHI; KUHNEN; BOMFIM, 2011).

Em suma, atividades de EA estão além de reproduzir conceitos sobre água, lixo, reciclagem, sustentabilidade. Porém, buscam a transformação no contexto cultural e social de crianças e jovens, ou seja, mudanças em seu processo psicossocial, proporcionando não apenas um comportamento responsável ambiental com o lixo, a água e a reciclagem, mas desenvolvendo pessoas que cuidem de seu ambiente doméstico, escolar, consigo mesmo e com sua coletividade (os outros). 
Partindo destas concepções, o programa de educação ambiental Pequenos Guias do Bosque da Ciência, ao longo dos seus 15 anos, não estava interessado apenas em desenvolver o domínio intelectual sobre temáticas socioambientais, mas possibilitar atividades que permitissem transformações subjetivas, psicossociais dos jovens e, assim, serem protagonistas de suas histórias.

\section{Método e técnicas de pesquisa}

A primeira etapa da pesquisa seguiu os trâmites devidamente aprovados pelo Comitê de Ética em Pesquisa (CEP/INPA). Em seguida, foi realizado o levantamento dos arquivos do Laboratório de Psicologia e Educação Ambiental (LAPSEA), para verificar o total de participantes distribuídos nas 15 turmas do projeto Pequenos Guias do Bosque da Ciência, e, assim, elaborar o desenho amostral da pesquisa.

A composição da amostra se deu de modo aleatório estratificado, considerando o número total de participantes (457) proporcional ao número de participantes (de dois a quatro de cada ano) de cada uma das 15 turmas entre 1995 e 2008, e mantendo uma equidade na distribuição de gênero. Para a seleção da amostra, foi realizado um sorteio conforme esses critérios de inclusão.

O estudo é baseado numa abordagem qualitativa, do tipo exploratório-descritivo. Foram entrevistados 48 ex-participantes $(\mathrm{F}=24 ; \mathrm{M}=24)$, com idade de 13 a 28 anos de idade. Utilizou-se, como técnica, um roteiro semiestruturado.

As entrevistas foram agendadas conforme a disponibilidade dos participantes, nas residências ou no Bosque da Ciência. O encontro do pesquisador com o jovem se iniciava com a apresentação do Termo de Consentimento Livre e Esclarecido (TCLE). Após a aceitação, a entrevista era gravada em um aparelho mp3, com duração média de quarenta a sessenta minutos. As perguntas conduzidas abordaram: as vivências dos jovens nas três fases do projeto, aspectos pessoais e sociais desenvolvidos durante a participação no projeto, e a mobilização sobre as questões socioambientais.

Após esta fase de coleta de dados, as entrevistas foram transcritas e organizadas no programa Microsoft Excel. O tratamento se deu a partir da análise de conteúdo do tipo categorial, proposta por Bardin (1977), a qual se caracteriza pela decodificação de um texto em diversos elementos que são classificados e formam agrupamentos. Adicionalmente, foram efetuadas estatísticas descritivas para identificação do quantitativo existente em cada categoria do estudo.

\section{Resultados e discussão}

A partir das análises, foi possível identificar que as atividades do projeto Pequenos Guias do Bosque da Ciência propiciaram, aos jovens, mudanças no ambiente escolar, familiar e com o meio ambiente. A seguir, os resultados serão destrinchados a partir de cada aspecto citado. 


\section{O jovem e o ambiente escolar}

Neste aspecto, se identificaram três categorias: (1) Aspectos psicossociais; (2) Aprendizagem; (3) Nenhuma contribuição do programa.

Conforme o primeiro grupo, aspectos psicossociais, $62,5 \%(\mathrm{n}=30)$ dos jovens afirmam que a participação no projeto promoveu mudanças em seu desenvolvimento psicossocial em dois aspectos: (1) A superação da vergonha de falar em público, a qual contribuiu nas apresentações dos seminários escolares e nas relações sociais com os colegas de classe; (2) Comprometimento com as regras da escola, horário e disciplina em sala de aula, e no desempenho escolar.

[...] Projeto ajudou não de uma forma direta, porque se você passa a ter uma certa responsabilidade, por exemplo, com as pessoas que você ia guiar, então você passa a ter mais responsabilidade e, consequentemente no seu dia-a-dia. Na escola você tem que ter essa responsabilidade, com suas notas [...]

Como eu sempre falei pra você, pelo fato de você ficar mais desenvolto, poder falar em público sem tá tremendo, sem tá com medo, sem tá nervosa. E nos trabalhos que a gente tem que fazer, esse tipo de coisa, era isso eu lembrava: Ab! eu falo pra'quele monte de gente lá eu não vou falar pros meus colegas?! Ai comecei...

Na segunda categoria, aprendizagem, 35,41\% $(n=17)$ dos jovens afirmam que o projeto contribuiu no processo de aprendizagem sobre as temáticas da fauna e flora do Bosque da Ciência e Amazônia, e sobre educação ambiental, o que permitiu a obtenção de notas positivas em disciplinas e seminários escolares que abordavam temáticas socioambientais e biológicas.

Ajudou sim. Ajudava mais na área de ciências. Sempre ajudou. Sempre quando caía sobre negócio de mamifero, sempre já tinha em mente do que, do que era sobre os mamiferos, tudinho. Sempre me saía bem nas provas. Nessa parte de meio ambiente.

Na escola? Ajudou sim. Foi que nem eu falei, o conhecimento. Se tiver que explicar alguma coisa sobre natureza, animais, a gente vai tá mais preparado que outros. Pra levar e defender a natureza.

Por fim, o último grupo, nenhuma contribuição do programa, com apenas $2 \%$ $(n=1)$ dos jovens, afirma não identificar mudanças no ambiente escolar.

Não. Porque não tinha nada a ver. Porque era só... era animais, plantas. Então, não tinha muita coisa entendeu? Pra conciliar.

A partir destes resultados, se constatou que os jovens relataram mudanças no ambiente escolar com a participação no programa de educação ambiental. Na primeira categoria definida como aspectos psicossociais, $62,5 \%$ afirmaram mudanças nas relações sociais com os colegas, superação da vergonha em falar em público e comprometimento com a escola. 
Estas características apresentadas podem ser explicadas a partir da contextualização do projeto. A participação na primeira fase do programa, Formação Educacional Crítica, insere os jovens num processo de compromisso, solidariedade e cooperação com o programa, as atividades e os colegas.

É a partir da Atuação e Interação no Bosque da Ciência, segunda fase do programa, que os jovens se tornam Pequenos Guias. Esta atividade é identificada, por Higuchi e Farias (2002, p. 34), como exercício de "(re)construção da cidadania", pelo fato de os jovens se apropriarem socialmente do espaço físico do Bosque da Ciência. Quando os jovens assumem esse papel, colocam em prática os conhecimentos adquiridos na fase anterior (Formação Educacional Crítica) e se apropriam do ambiente em que estão atuando, consideram o mundo que os rodeia também seu. Assim, os jovens desenvolvem responsabilidade e cuidado com o ambiente em que estão atuando, com os visitantes, os colegas, com o conhecimento adquirido e, também, com o próprio programa.

Além disto, esta mesma fase promoveu desenvoltura da comunicação dos jovens, a qual contribuiu tanto para a apresentação de seminários escolares, como na relação com os colegas de classe, superando a timidez. Este fato é possível, por conta de os mesmos terem estabelecido diferentes interações com os visitantes no Bosque da Ciência.

Frente a estes aspectos descritos, é possível identificar que as vivências do programa se estenderam para o ambiente escolar, ou seja, o processo de mudanças pessoais não ficou restrito apenas ao ambiente em que ocorriam as atividades, Bosque da Ciência, mas acompanhou uma modificação no contexto social desses jovens, neste caso, a escola. Em outras palavras, eles transportaram para a escola: a dedicação dos estudos socioambientais na Formação Educacional Crítica, e apropriação do ambiente e exercício de cidadania do Bosque da Ciência na Atuação e Interação no Bosque da Ciência.

Nesse sentido, é importante compreender que o indivíduo e o ambiente consistem em um processo dinâmico, capaz de construir conhecimento e, ao mesmo tempo, transformar seu meio (HIGUCHI; FARIAS, 2002). Nesse sentido, quando há transformação da pessoa, há transformação do seu espaço e lugar para viver (INGOLD, 1990).

Ainda, em outra categoria identificada como aprendizagem, 35,41\% relataram o domínio sobre os assuntos da fauna e flora da Amazônia, e educação ambiental. Esta aprendizagem remete à primeira fase do projeto (Formação Educacional Crítica), em que os encontros semanais com pesquisadores e educadores promoviam discussões sobre questões socioculturais, ambientais e de ecoturismo por, aproximadamente, seis meses (HIGUCHI; FARIAS, 2002).

O conhecimento aprendido no programa complementou os conteúdos programáticos da escola, o que nos mostra uma ampliação no repertório cognitivo dos jovens. Vale ressaltar que a apropriação do conhecimento ambiental é o início para mudanças comportamentais em relação ao meio ambiente.

Viégas e Guimarães (2004) afirmam que adquirir conhecimento sobre o ecossistema é o início para uma sensibilização sobre os problemas a eles relacionados, e construir um comportamento ecologicamente correto.

Conforme Smyth (1995), reafirmados por Higuchi (2009), o conhecimento ambiental acontece a partir de encontros em que pesquisadores e especialistas das áreas ecológicas e sociais discorrem sobre informações e redes de conexões para que a vida ocorra em equilíbrio. A autora alerta que a compreensão do mundo e suas características não são suficientes para a 
transformação do comportamento, mas são necessárias para que ocorram mudanças gradativas com o meio ambiente.

Dessa forma, a relação dos ex-pequenos guias com o ambiente escolar permite refletir sobre os programas de educação ambiental, os quais não devem ser vistos e desenvolvidos com o objetivo, apenas, de promover o domínio intelectual sobre temáticas socioambientais e gerar mudanças comportamentais, mas possibilitar vivências de solidariedade, compromisso, cooperação e cidadania, consigo mesmo, com os outros e os demais ambientes e atividades da vida, e, assim, possibilitar, ao jovem, se tornar uma pessoa participativa na inscrição da sua história.

\section{$O$ jovem e o ambiente familiar}

Em relação à família e os jovens, foi possível identificar que a participação no projeto promoveu mudanças nos seguintes aspectos: (1) Comportamento ecológico; (2) Socialização; (3) Confiança e reconhecimento; (4) Financeiramente; (5) Nenhuma mudança.

Os jovens do primeiro grupo, cidadania socioambiental, com $50 \%(\mathrm{n}=24)$, afirmam que a participação no projeto gerou mudanças no comportamento ecológico tanto deles quanto da família. Tais mudanças se referem ao cuidado e zelo com o ambiente doméstico, economia de luz e água, e prática da coleta seletiva. Isto foi possível devido ao conhecimento dos jovens sobre as problemáticas socioambientais, o qual compartilharam com os familiares.

Na organiz̧ação da familia a também ajudar no... na própria limpeza, organização da casa também e na conscientização das pessoas também [...].

Ajudou eu ensinar minha mãe a reciclar o lixo, eu falava para ela que era importante. [...] ela abria a geladeira toda hora e eu falava que gastava muita energia, eu ajudei ela numa forma de abaixar a energia.

A socialização foi outro aspecto identificado, compondo o segundo grupo, com 33,5\% $(n=16)$. Os jovens relataram que a participação no programa favoreceu maior envolvimento com a família, promovendo diálogo sobre as atividades ocorridas no Bosque da Ciência e passeios familiares no mesmo local. Esta interação estabeleceu uma relação de respeito com os pais e irmãos, e responsabilidade com as regras da família, como horário, organização e limpeza dos objetos pessoais.

Na minha casa? O projeto me ajudou na parte de diálogo com a minha família. Que sempre quando eu saía, eu sempre falava: Poxa, hoje foi legal, não sei o quê. Sempre falava com eles, tudinho sobre o que tinha acontecido, o que ocorreu no dia todinho.

O que o projeto me ajudou? É... Na realidade... Me ajudou a... A viver mais em familia, entendeu? Porque ali era uma família que eu tinha no bosque e quando eu chegava em casa, me ajudou até na educação de com os meus pais mesmo entendeu? Porque no bosque eu era uma pessoa e eu não queria ser outra pessoa dentro de casa, assim como eu agia ali com a Solange com o pessoal que faria comigo, os meus amigos. Eu tratava eles bem en queria tratar meus pais também, mens irmãos dentro de casa. 
No terceiro grupo, confiança e reconhecimento, com 10,5\% ( $\mathrm{n}=5)$, os jovens perceberam que a participação no projeto proporcionou, aos pais, uma relação de confiança com o projeto e com as atividades desenvolvidas no Bosque da Ciência. Ainda, os pais reconheciam o projeto como uma ocupação, elogiando a participação dos filhos.

O que o Projeto me ajudou na minha casa... Como eu disse, naquele momento, somos três irmãos, meu irmão tinha 24 anos e o outro 17, e eu tinha 10/12, acredito que a questão da preocupação que eu não passava para minha mãe. Ela tinha certeża que eu estava num lugar seguro, aqui no Bosque da Ciência e na escola também.

Bom... minha participação aqui foi bom só pelo fato... pelo fato de... de tá num lugar minha mãe saber que eu tava aprendendo, essas coisas assim né? Bem estável, essas coisas assim. Foi só o que... Foi só o que nos causou.

No penúltimo grupo, financeiramente, com 4\% ( $n=2)$, os jovens afirmaram que a bolsa-auxílio que recebiam durante a participação do projeto proporcionava independência na compra de objetos pessoais e, também, ajudava em casa. Vale ressaltar que esta bolsa-auxílio foi apenas nas primeiras turmas do projeto.

Na época eu tinha uma bolsa que o INPA pagava e que me ajudava a ter minhas coisas. Podia comprar uma roupa, um tênis, sem ter que ficar dependendo dos meus pais, nem de outras pessoas.

Na minha casa? Olha, naquele tempo né? assim, a gente tinha uma bolsa né? a gente recebia. Ajudou bastante, porque nós somos quatro aí o dinheiro que a gente pegava, eu não tinha aquela mentalidade: A h eu vou gastar tudo, vou comprar roupa, vou comprar bolacha, chocolate. Não, dava tudo pra minha mãe, toma a senhora compra o que é preciso [...].

Por fim, o último grupo, nenhuma mudança, com apenas $2 \%(\mathrm{n}=1)$, afirmou não identificar nenhuma mudança em seu comportamento no ambiente familiar e nem nos membros da sua família.

Não ajudou, mas também num... ficou do jeito que tava. Entendeu?

Os resultados mostram que a participação dos jovens no programa repercutiu em seu ambiente familiar. Os jovens foram capazes de modificar as ações de seus familiares sobre as questões socioambientais (50\%). Esta categoria, cidadania socioambiental, ilustra a participação dos jovens como protagonistas das questões socioambientais em seu ambiente doméstico, o qual promoveu mudanças nos familiares. Em outras palavras, os jovens atuaram como cidadãos em seu próprio ambiente doméstico/familiar.

"O ser humano como ser biologicamente social constrói seu conhecimento, seu sistema de significados da realidade na interação com outras pessoas e as re-elabora num processo dinâmico e contínuo" (KUHNEN; HIGUCHI, 2009, p. 102). 
Reigota $(2007,2008)$ afirma que a cidadania é a principal característica da educação ambiental, ou seja, busca-se a formação e o exercício da cidadania, a fim de as pessoas serem corresponsáveis em defesa da qualidade de vida, capazes de pensarem em suas práticas cotidianas. Para o autor, cidadania está relacionada com identidade e pertencimento de uma coletividade.

Jacobi (2003) afirma que a educação ambiental para a cidadania deve formar cidadãos conscientes em nível local e planetário. O objetivo do processo educativo é desenvolver, nas pessoas, uma nova relação com a sociedade e o seu ambiente (HIGUCHI; ZATTOTONI; BUENO, 2012).

Por outro lado, além da mudança descrita anteriormente, foi possível constatar que o programa promoveu o estreitamento de laços afetivos e socialização entre as famílias e os jovens do programa. Os familiares atuaram como agentes participativos na construção psicossocial de seus filhos. Estes aspectos definiram as categorias: socialização (33,5\%); confiança e reconhecimento $(10,5 \%)$.

Feijó e Macedo (2012) estudaram os projetos sociais que envolvem jovens e o impacto nas famílias. As autoras constataram que, neste processo, houve impactos positivos, como: a melhora na comunicação entre o jovem e a família, melhora nas relações com parentes e vizinhos, e na própria participação social dos jovens. Assim, concluem que os projetos sociais não podem desconsiderar o papel da família, pois, será neste contexto que os jovens irão alcançar autonomia e atuar como protagonistas.

A participação pode ser: a família conhecer os objetivos e funcionamento dos projetos, acompanhar seu andamento por meio de conversas com o jovem ou cobrar resultados. Ainda, podem dividir planos de futuro com o jovem e acompanhar o seu desenvolvimento (FEIJÓ; MACEDO, 2012).

Diante destes aspectos, o programa Pequenos Guias vai ao encontro do estudo proposto, pois, teve o cuidado de envolver e integrar a família com reuniões e encontros sobre o programa, a fim de que a participação dos jovens fosse promover mudanças na família (HIGUCHI; FARIAS, 2002).

Nesse sentido, esta relação - jovem, família e atividades de educação ambiental - forma um tripé que pode gerar mudanças em relação às questões socioambientais no ambiente familiar, mas, por outro lado, permite tornar este ambiente mais participativo no desenvolvimento psicossocial de seus filhos, promovendo o estreitamento de laços afetivos e de socialização nesta relação.

\section{$O$ jovem e o meio ambiente}

Sobre a relação dos jovens com o meio ambiente, o estudo identificou três categorias neste quesito: (1) Cuidado ambiental; (2) Disseminação sobre o cuidado ambiental; (3) Intervenção pró-ambiental.

No primeiro grupo, cuidado ambiental, com $77 \%(\mathrm{n}=37)$, os jovens relatam algumas ações positivas com o meio ambiente em seu cotidiano, como: não utilizar saco plástico, não jogar lixo nas ruas/jogar o lixo no local correto, economizar a água e a energia, não poluir os igarapés, cuidar do ambiente doméstico, não queimar e nem cortar as árvores da casa, ter mais cuidado com animais e plantas e plantar árvores em casa. Estas ações são, ainda, acompanha- 
das da disseminação e intervenção em comportamentos de descuido ambiental de familiares, amigos e colegas de trabalho.

Ah sim, eu procuro da minha parte. Procuro não poluir os rios, procuro é... colocar o lixo no local certo, é manter sempre limpo o ambiente onde eu, onde eu vivo, onde eu trabalho, é... Procuro dizer pras pessoas manterem dessa forma também. E acho que isso me tornou um pouquinho mais responsável em relação à essas coisas.

Bom... Eu aprendi que... Esse negócio de jogar lixo na rua, isso ai eu já aprendi lá no Inpa mesmo, entendeu? Meus pais eles eram bem... Não tinham muito estudo, então eles não ensinavam essas coisas e no Inpa eu aprendi a cuidar, não jogar lixo na rua, porque se chover vai entupir, entendeu? Ter esses pequenos cuidados, pequenas coisas, mas que faz uma diferença. Entendeu?

No grupo seguinte, disseminação sobre o cuidado ambiental, com 13\% ( $n=6)$, os jovens estão preocupados em disseminar informações aos colegas do trabalho, familiares e amigos sobre a importância de preservar e sobre o lixo.

Responsável conscientizando pessoas. Conscientizando minha família, meus amigos sobre a importância da preservação do meio ambiente.

Eu falo pras as pessoas pra ela reciclarem o lixo, que mais tarde eles podem ensinar para os seus filhos, netos, bisnetos, que o mundo possa ser cada vez. melhor, sem a poluição.

O terceiro grupo, intervenção pró-ambiental, com 10\% $(\mathrm{n}=5)$ dos jovens, intervém sobre o comportamento, ou seja, eles interferem numa ação imediata de familiares e colegas que apresentem descuido ambiental.

Tanto é que a minha mulher me chama de chato quando a gente sai por ai, eu compro uma garrafinha de água ou alguma coisa pra comer ela pega, ela tem o costume de pegar e jogar onde ela está. Ai eu mando ela juntar, ela: Pra quê? Todo mundo faz. isso. Não, não é porque todo mundo faz que você vai fazer. Eu falei, não tá certo, guarda a garrafa quando tu encontrar um canto tu joga na lixeira. Então ela me chama de chato por isso, mas eu sei que é o correto.

[...] Então, nesse estágio que eu faço eu... eu procuro trabalhar bastante com as crianças questões voltadas ao meio ambiente, não sujar, não poluir, não desmatar, essa questão toda eu coloco em observação [...]

As três categorias descritas, cuidado ambiental (77\%), disseminação sobre o cuidado ambiental (13\%) e intervenção pró-ambiental (10\%), de modo geral, apresentam relações positivas com o meio ambiente. A primeira categoria concretiza ações diretas de cuidado com 
o meio ambiente, acompanhado pela disseminação e intervenção em comportamentos de familiares, amigos e colegas de trabalho que descuidam do ambiente. Nesse sentido, poderíamos situar a prática de uma cidadania ambiental desses jovens.

Sato (2002 apud HIGUCHI; AZEVEDO, 2004) nos apresenta os processos de mudanças presentes na educação ambiental: Sensibilização ambiental, se trata de um alerta em que o educando é inserido num mundo a ser descoberto; Compreensão ambiental, possibilita a divulgação de informações específicas quanto ao ecossistema, seus elementos, características e relações biofísicas; Responsabilidade ambiental, consiste no processo de reflexão em que o educando se posiciona como elemento no ecossistema, ou seja, como alguém que pode transformar, manter e preservar o mesmo; Competência ambiental, significa participar de processos educativos que almejam uma avaliação voltada ao desenvolvimento de capacidades e ação sobre o ambiente; Cidadania ambiental, envolve ações de participação e mobilização em conjunto com outras pessoas para solucionar problemas encontrados na relação pessoa com ambiente, ou, até mesmo, numa prevenção de possíveis riscos ambientais que poderão surgir de comportamentos ambientais inadequados.

A partir de outro olhar, podemos situar a cidadania ambiental como um comportamento ecológico. Este consiste em "ação humana que visa contribuir para proteger o meio ambiente ou para minimizar o impacto ambiental de outras atividades. Ele pode ser intencional ou não, e, ainda, ser aprendido e aplicado na vida cotidiana” (PATO; CAMPOS, 2011, p. 122).

Identifica-se que as questões ambientais nos jovens não estão apenas no campo do pensamento, mas já atingiram uma maturidade cognitiva que permite converter em ação concreta e direta. Nesse sentido, é possível observar questões presentes de cognição ambiental nos jovens. Higuchi, Kuhnen e Bomfim (2011) explicam que envolve processos de armazenamento, evocação e uso das informações do meio ambiente para resolução de questões cotidianas e, também, nas relações sociais.

O processo de estruturas mentais são dimensões interligadas na construção de conceitos, ou seja, há estruturas internas interagindo com a realidade do sujeito que reflete na interação com o meio ambiente (HIGUCHI; FARIAS, 2002). Nesse sentido, é possível afirmar que a participação dos jovens acompanhou mudanças cognitivas em relação ao meio ambiente, capaz de atuar em prol da proteção do meio ambiente.

Por outro lado, a segunda e terceira categorias, não menos importantes, situam as ações dos jovens apenas na disseminação de cuidado ambiental, e intervenção direta em comportamentos de descuido ambiental de familiares, amigos e colegas de trabalho. Isto é, os jovens apresentam apenas uma responsabilidade ambiental, conforme descrito anteriormente.

Neste aspecto, os jovens atingem um grau de reflexão do que é possível fazer em prol do meio ambiente; por isso, sentem-se responsáveis em mudar os hábitos dos outros, mas não atingem uma concretização de suas ações. Contudo, é importante pontuar que esta responsabilidade não deve ser vista como algo negativo, mas como uma pequena mudança para os jovens alcançarem a cidadania ambiental.

Assim, se identificou que o projeto alcançou mudanças significativas na relação dos jovens com o meio ambiente, atingindo o grau mais alto, a cidadania ambiental; e, também, aqueles jovens que se encontram em responsabilidade ambiental, mas devem ser encarados como jovens que têm potencial para fazer uma mudança mais profunda com o meio ambiente. 


\section{Considerações}

Neste artigo, foram apresentados os efeitos da participação dos jovens em um projeto de educação ambiental, Pequenos Guias do Bosque da Ciência, em seu desenvolvimento psicossocial. O estudo identificou, nos jovens, mudanças no ambiente escolar, familiar e com o meio ambiente.

O ambiente escolar dos jovens sofreu mudanças significativas como: a superação da vergonha, desenvoltura da comunicação em apresentações de seminários escolares, estreitar relações sociais com os colegas, compromisso com as questões escolares, além de contribuir para o desempenho acadêmico.

Em relação ao ambiente familiar, se identificou que os familiares tiveram mudanças de hábitos em relação às questões socioambientais, após a atuação dos filhos como protagonistas socioambientais. Ainda, houve estreitamento de laços afetivos e socialização entre os familiares e os jovens.

Sobre os jovens e o meio ambiente, foi possível constatar a atuação da cidadania ambiental e ações de responsabilidade ambiental, em que os jovens buscam disseminar e/ou intervir em comportamentos de descuido ambiental.

Estes resultados proporcionam uma reflexão sobre o papel da educação ambiental, o qual se apresenta para além de conhecimentos ambientais. O envolvimento de jovens em programas de educação ambiental dá voz para esse público desenvolver mudanças psicossociais e construir sua trajetória de vida pautada no compromisso social, ou seja, no exercício da cidadania. Acredita-se que, se os jovens são motivados a estabelecerem compromissos com o meio ambiente em que estão inseridos, este exercício se estenderá para outros ambientes, como a escola, a família, a comunidade, e outros, transformando seu mundo individual e coletivo.

\section{Referências}

ALBUQUERQUE, D. S. Protagonismo socioambiental: o olhar de jovens participantes de programas de educação ambiental. 2013. 53 f. Trabalho de conclusão de curso (Graduação em Psicologia) - Faculdade de Psicologia, Universidade Federal do Amazonas, Manaus, 2013. BARDIN, L. Análise de conteúdo. Lisboa: Edições 70, 1977.

BARRA, V. M. M. Exploração de necessidades socioeducativas e análise de modelos formativos de educação ambiental com caráter experimental. Educar em Revista, Curitiba, n. 27, p. 111-128, jan./jun. 2006. Disponível em: <http://dx.doi.org/10.1590/S010440602006000100008>. Acesso em: 02 fev. 2014.

BEE, H. O ciclo vital. Porto Alegre: Artes Médicas, 1997.

CARVALHO, I. C. M. Educação ambiental crítica: nomes e endereçamentos da educação. In: LAYRARGUES, P. P. (Coord.). Identidades da educação ambiental brasileira. Brasília: Ministério do Meio Ambiente, 2004. p. 13-24. 
CASTRO, L. R. A politização (necessária) do campo da infância e da adolescência. Revista Psicologia Política, São Paulo, v. 7, n. 14, 2007. Disponível em: <http://pepsic.bvsalud. org/pdf/rpp/v7n14/v7n14a05.pdf >. Acesso em: 25 maio 2015.

CURRIE, K. L. Meio ambiente: interdisciplinaridade na prática. Campinas: Papirus, 1998.

FEIJÓ, M. R.; MACEDO, R. M. S. Família e projetos sociais voltados para jovens: impacto e participação. Estudos de Psicologia, Campinas, v. 29, n. 2, p. 193-202, abr./jun. 2012. Disponível em: <http://dx.doi.org/10.1590/S0103-166X2012000200005>. Acesso em: 29 maio 2015.

FERNANDES, F. O. P.; HIGUCHI, M. I. G. Significados atribuídos pelos jovens à participação e mobilização grupal em atividades socioambientais. Manaus: INPA, 2014. (Relatório técnico bolsa PIBIC/INPA/CNPq/MCTI- PAIC/FAPEAM).

HIGUCHI, M. I. G. Construindo caminhos de protagonismo socioambiental com adolescentes. In: CASTRO, L. R.; BESSET, V. L. (Org.). Pesquisa-intervenção na infância e juventude. Rio de Janeiro: FAPERJ: Nau Editora, 2008. p. 224-243.

. Crianças e meio ambiente: dimensões de um mesmo mundo. In: NOAL, F.; BARCELOS, V. (Org.). Educação ambiental e cidadania: cenários brasileiros. Santa Cruz do Sul: EDUNISC, 2003. p. 201-229.

. Educação ambiental e gestão pública. In: HIGUCHI, N. et al. Governos locais amazônicos e as questões climáticas globais. Manaus: Edição dos Autores, 2009. p. $82-27$.

Projeto Pequenos Guias do Bosque da Ciência. Manaus: INPA, 1994.

HIGUCHI, M. I. G.; AZEVEDO, G. C. Educação como processo na construção da cidadania ambiental. Revista Brasileira de Educação Ambiental, Brasília, v. 1, n. 0, p. 63-70, nov. 2004. Disponível em: < http://www.academia.edu/9675257/Educacao_como_ processo_na_construcao_da_cidadania_ambiental>. Acesso em: 23 maio 2015.

HIGUCHI, M. I. G.; FARIAS, M. S. M. Pequenos Guias do Bosque da Ciência: trajetória de uma experiência de educação ambiental com crianças na Amazônia. Manaus: INPA, 2002.

HIGUCHI, M. I. G.; MOREIRA JÚNIOR, W. Educação ambiental e movimentos sociais: espaços paralelos ou compartilhados? Pesquisa em Educação Ambiental, Ribeirão Preto, v. 4, n. 2, p. 165-174, jan. 2009. Disponível em: < http://www.revistas.usp.br/pea/article/ view/30068>. Acesso em: 26 maio 2015.

HIGUCHI, M. I. G.; ALVES, H. H. S. C.; SACRAMENTO, L. C. A arte no processo educativo de cuidado pessoal e ambiental. Currículo sem Fronteiras, v. 9, n. 1, p. 231-250, jan./jun. 2009. Disponível em: <http://www.curriculosemfronteiras.org/vol9iss1 articles/ higuchi-alves-sacramento.pdf > . Acesso em: 02 fev. 2014.

HIGUCHI, M. I. G.; KUHNEN, A.; BOMFIM, Z. A. C. Cognição ambiental. In: SYLVIA, C.; ELALI, G. A. (Org.). Temas básicos em psicologia ambiental. Petrópolis: Vozes, 2011. p. 105-121. 
HIGUCHI, M. I. G.; ZATTONI, M.; BUENO, F. P. Educação ambiental em contextos não escolares: definindo, problematizando e exemplificando. Pesquisa em Educação Ambiental, Rio Claro, v. 7, n. 2, p. 119-131, jan. 2012. Disponível em: <http://www.revistas. usp.br/pea/article/view/55967/59349>. Acesso em: 26 maio 2015.

INGOLD, T. An anthropologist looks at biology. Man, New Series, Chichester, v. 25, n. 2, p. 208-229, June, 1990. Disponível em: < http://postcog.ucd.ie/ files/ingold90.pdf >. Acesso em: 25 maio 2015.

JACOBI, P. Educação ambiental, cidadania e sustentabilidade. Cadernos de Pesquisa, São Paulo, n. 118, p. 189-205, mar. 2003. Disponível em: < http://dx.doi.org/10.1590/S0100$15742003000100008>$. Acesso em: 02 fev. 2014.

JANKE, N.; TOZONI-REIS, M. F. C. Produção coletiva de conhecimentos sobre a qualidade de vida: por uma educação ambiental participativa e emancipatória. Ciência \& Educação, Bauru, v. 14, n. 1, p. 147-157, 2008. Disponível em: <http://dx.doi. org/10.1590/S1516-73132008000100010>. Acesso em: 02 fev. 2014.

KUHNEN, A.; HIGUCHI, M. I. G. Campos de encontro da psicologia e educação na construção de comportamentos socioambientais. Utopía y Praxis Latinoamericana, Punto Fijo, v. 14, n. 22, p. 101-108, jan./mar. 2009.

LAYRARGUES, P. P. Educação para gestão ambiental: a cidadania no enfrentamento político dos conflitos socioambientais. In: LOUREIRO, C. F. B.; LAYRARGUES, P. P.; CASTRO, R. S. (Org.). Sociedade e meio ambiente: a educação ambiental em debate. São Paulo: Cortez, 2000. p. 87-155.

LEVISKY, D. L. Adolescência: reflexões psicanalíticas. 2. ed. rev. atual. São Paulo: Casa do Psicólogo, 1998.

LOUREIRO, C. F. B. Educar, participar e transformar em educação ambiental. Revista Brasileira de Educação Ambiental, Brasília, v. 1, n. 0, p. 13-70, nov. 2004. Disponível em: <http://www.academia.edu/9675257/Educacao_como_processo_na_construcao_da_ cidadania_ambiental $>$. Acesso em: 23 maio 2015.

MOREIRA, J. O.; ROSÁRIO, A. B.; SANTOS, A. P. Juventude e adolescência: considerações preliminares. Psico, Porto Alegre, v. 42, n. 4, p. 457-464, out./dez. 2011. Disponível em: <http://revistaseletronicas.pucrs.br/ojs/index.php/revistapsico/article/view/8943>. Acesso em: 25 maio 2015.

PAPALIA, D. E.; OLDS, S. W.; FELDMAN, R. D. Desenvolvimento humano. São Paulo: Mcgraw-Hill, 2009.

PATO, C. M. L.; CAMPOS, C. B. Comportamento ecológico. In: SYLVIA, C.; ELALI, G. A. (Org.). Temas básicos em psicologia ambiental. Petrópolis: Vozes, 2011. p. 122-143.

PELICIONI, M. C. F. Educação ambiental, qualidade de vida e sustentabilidade. Saúde e Sociedade, São Paulo, v. 7, n. 2, p. 19-31. 1998. Disponível em: <http://dx.doi. org/10.1590/S0104-12901998000200003 >. Acesso em: 02 fev. 2014. 
REIGOTA, M. A. S. Cidadania e educação ambiental. Psicologia \& Sociedade, Porto Alegre, v. 20, p. 61-69, 2008. Edição especial. Disponível em: <http://dx.doi.org/10.1590/ S0102-71822008000400009>. Acesso em: 26 maio 2015.

. Ciência e sustentabilidade: a contribuição da educação ambiental. Avaliação: revista de avaliação da educação superior, Sorocaba, v. 12, n. 2, p. 219-232, jun. 2007. Disponível em: <http:/ /www.redalyc.org/articulo.oa?id=219114877003>. Acesso em: 02 fev. 2014.

. O que é educação ambiental? São Paulo: Brasiliense, 1994.

SAUVÉ, L. Uma cartografia das correntes em educação ambiental. In: SATO, M.; CARVALHO, I. C. M. (Org.). Educação ambiental: pesquisa e desafios. Porto Alegre: Artmed, 2005a. p. 17-44.

. Educação ambiental: possibilidades e limitações. Educação e Pesquisa, São Paulo, v. 31, n. 2, p. 317-322, maio/ago. 2005b. Disponível em: <http://www.redalyc.org/articulo. oa?id=29831212>. Acesso em: 23 maio 2015.

SILVA, C. R.; LOPES, R. E. Adolescência e juventude: entre conceitos e políticas públicas. Cadernos de Terapia Ocupacional, São Carlos, v. 17, n. 2, p. 87-106, jul./dez. 2009. Disponível em: <http://www.cadernosdeterapiaocupacional.ufscar.br/index.php/cadernos/ article/view/100>. Acesso em: 25 maio 2015.

SMYTH, J. C. Environment and education: a view of a changing scene. Environmental Education Research, Abingdon, v. 1, n. 1, p. 3-20, 1995.

SORRENTINO, M. et al. Educação ambiental como política pública. Educação e Pesquisa, São Paulo, v. 31, n. 2, p. 285-299, maio/ago. 2005.

VIÉGAS, A.; GUIMARÃES, M. Crianças e educação ambiental na escola: associação necessária para um mundo melhor? Revista Brasileira de Educação Ambiental, Brasília, v. 1, n. 0, p. 56-62, nov. 2004. Disponível em: <http://www.academia.edu/9675257/ Educacao_como_processo_na_construcao_da_cidadania_ambiental $>$. Acesso em: 23 maio 2015. 